\title{
Influence of Caloric Vestibular Stimulation on Body Experience in Healthy Humans
}

\author{
Andreas Schönherr and Christian Albrecht May* \\ Institute of Anatomy, Medical Faculty Carl Gustav Carus, Technical University Dresden, Dresden, Germany
}

The vestibular system has more connections with and influence on higher cortical centers than previously thought. These interactions with higher cortical centers and the phenomena that they elicit require a structural intact cerebral cortex. To date, little is known about the role and influence of the vestibular system on one's body experience. In this study we show that caloric vestibular stimulation (CVS) in healthy participants has an effect on the perceptive component of one's body experience. After CVS all participants showed a statistically significant difference of thigh width estimation. In contrast to previous studies, which demonstrated an influence of CVS on higher cortical centers with an intact cerebral cortex both the cognitive and affective component of body experience were not effected by the CVS. Our results demonstrate the influence of the vestibular system on body perception and emphasize its role in modulating different perceptive-qualities which contributes to our body experience. We found that CVS has a limited influence on one's conscious state, thought process and higher cortical functions.

OPEN ACCESS

Edited by:

Elizabeth B. Torres,

Rutgers University, USA

Reviewed by:

Fred W. Mast,

University of Bern, Switzerland

Frank Röhricht,

University of Essex, UK

${ }^{*}$ Correspondence:

Christian Albrecht May

albrecht.may@tu-dresden.de

Received: 10 March 2015 Accepted: 29 February 2016

Published: 11 March 2016

Citation:

Schönherr A and May CA (2016) Influence of Caloric Vestibular Stimulation on Body Experience in Healthy Humans.

Front. Integr. Neurosci. 10:14. doi: 10.3389/fnint.2016.00014
Keywords: caloric vestibular stimulation, body experience, body schema, body awareness, body image

\section{INTRODUCTION}

The vestibular system, originally conceived as a reflex system to generate and control spinal and ocular-motor movements (Palla and Lenggenhager, 2014), appears more interesting today. During the last few years, an increasing number of articles concerning the vestibular system have demonstrated new innervations and influences than previously thought. It interacts with numerous higher cortical centers, which presume an intact cerebral cortex. These interactions include the interpretation of tactile and heat stimuli (Ferrè et al., 2013a), the spatial discrimination of tactile stimuli (Ferrè et al., 2013b), mental imagery (Péruch et al., 2011), attention (Figliozzi et al., 2005), memory (Smith et al., 2010), risk behavior (McKay et al., 2013), mood (Preuss et al., 2014a), social interaction (Deroualle and Lopez, 2014), and even the desire and probability of purchasing a product (Preuss et al., 2014b). However, little is known about the influence and role of the vestibular system on body experience; the present knowledge is primarily based on studies involving pathological conditions: people with vestibular diseases may show "out-of-body-experiences" (Skworzoff, 1931), perception of absent body motion (vertigo; Curthoys and Halmagyi, 1995) or symptoms of depersonalization and derealization (Smith and Darlington, 2013). Furthermore a distorted body experience, which is a central part of different diseases and situations, can be influenced by caloric vestibular stimulation (CVS). These situations and diseases include neglect and anosognosia (Ramachandran et al., 2004), somatoparaphrenia (Bisiach et al., 1991), pain (Mast et al., 2014), camptocormia (Okada et al., 2012), mania (Levine et al., 2012), shape and position 
of phantom-limbs (André et al., 2001), and also anorexia nervosa (Schönherr and May, 2015). The main question leading to the present study concerned the role of the vestibular system on body experience in healthy participants. Our study focuses on the influence of CVS on the four different components of one's total body experience (perceptive, cognitive, affective and behavioral; Thompson, 1999). The perceptive component contains sensory information of all modalities regarding one's own body. It includes the perception of the body's dimensions as well as its orientation in space and is the basis of one's body image. The affective component includes the feelings regarding one's own body and is therefore the basis of one's body awareness. The third component is the cognitive component regarding thoughts and attitude towards one's own body. It is the basis of self image and ego. The last component is behavior and can be separated into motor (facial expressions, gestures, posture) and into social behavior. For a precise use of terms we adhered to the "Consensus Paper on terminological differentiation on various aspects of body experience" (Röhricht et al., 2005).

In the present study, we investigated the influence of CVS on different parts of body experience using established methods for perceptive (body-size estimation, silhouettetechnique) and cognitive components (questionnaires) as described in the "Materials and Methods" Section. This work was part of a project which previously investigated the influence of caloric irrigation on body experience of anorectic patients in an attempt to open a new therapeutic window for their treatment (Schönherr and May, 2015). Surprisingly we could also identify a distinct influence of vestibular system stimulation in non-anorectic volunteers. The quality of this influence might help to explain why the stimulation technique did not show the same results in anorexia nervosa compared with neglect or other conditions listed above.

\section{MATERIALS AND METHODS}

Thirty students of the Medical Faculty Carl Gustav Carus in Dresden were recruited by flyers and advertisement in lectures. Based on their own statements they did not suffer from any psychological or physical diseases, and the exclusion criteria consisted of body mass index (BMI) under 17.5, amenorrhea, malposition or inflammation of the external auditory canal, perforated eardrum, diseases of the vestibular system (previously known or detected during clinical examination), and conditions known to change body experience that is e.g., pregnancy, anorexia nervosa, depression, panic-attacks, hypochondria.

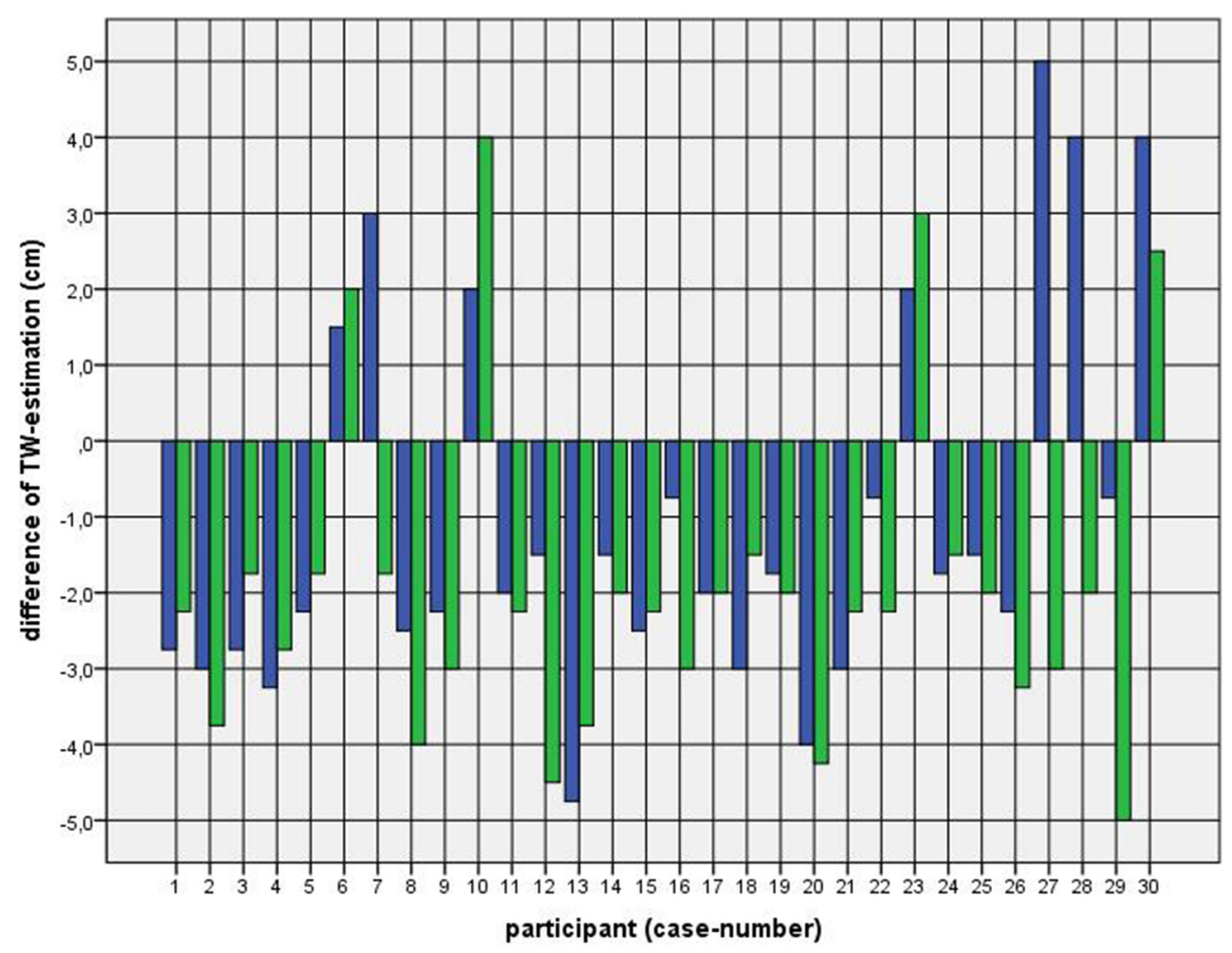

FIGURE 1 | Difference between mean of thigh width (TW) estimation before and first TW estimation after caloric vestibular stimulation (CVS). Key: blue-left-CVS; green-right-CVS. Annotation: negative difference-first estimated TW after CVS was thinner than mean of TW-estimation before CVS; positive difference-first estimated TW after CVS was wider than mean of TW-estimation before CVS. 


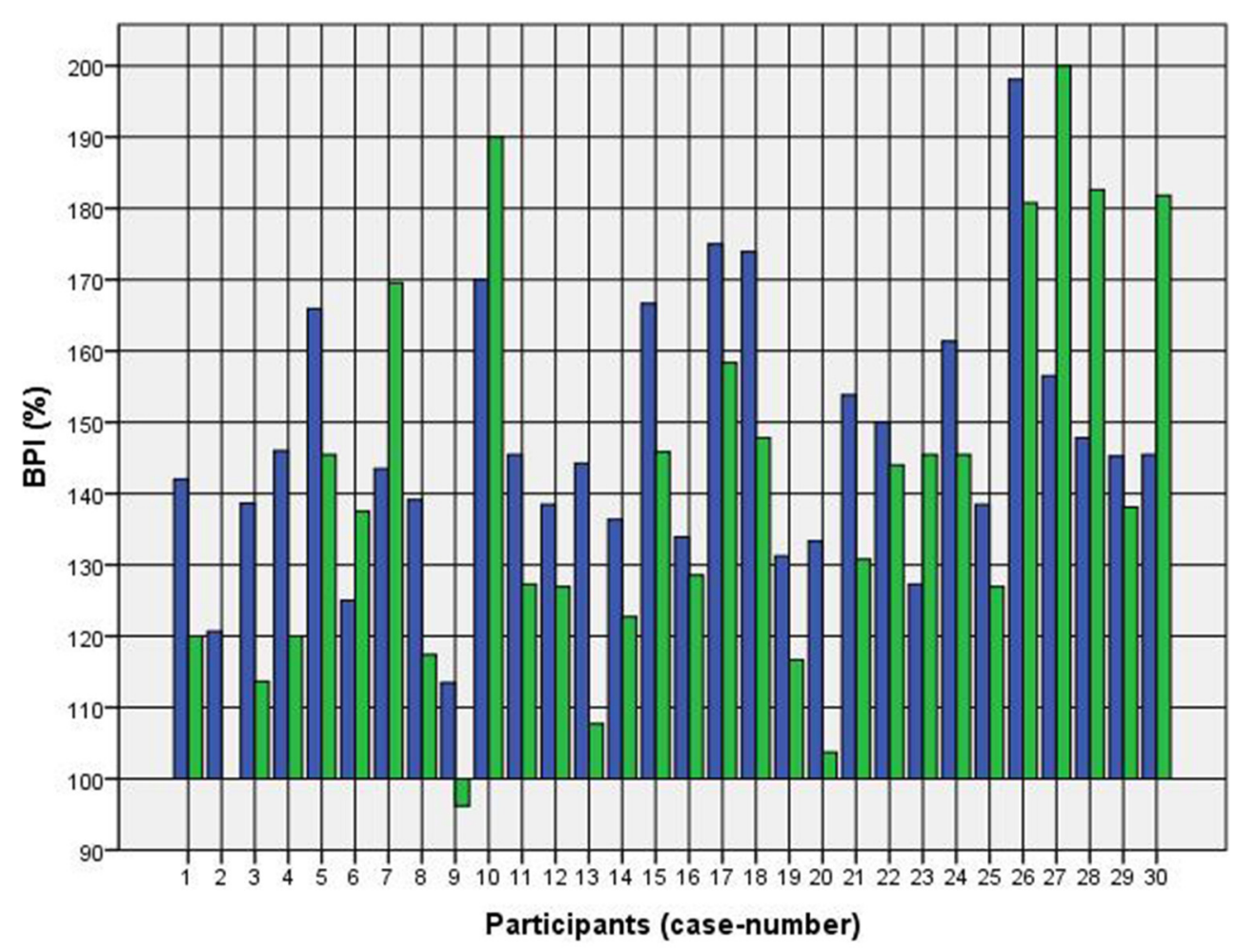

FIGURE 2 | Body Perception Index (BPI) before and after left CVS. Key: blue-BPI before CVS; green-BPI after CVS. Annotation: BPI > 100\% means overestimation of TW; $\mathrm{BPI}<100 \%$ means underestimation of TW.

To investigate the perceptive component of body experience, a body-size estimation technique (developed by Horn and Scholz, 2009) and a silhouette-technique (figure-scale developed by Thompson and Gray, 1995) were used. For body-size estimations, the students were asked to show the thigh width (in the middle of the thigh) with their hands (eyes covered). The thigh width was used since it has a reasonable size in order to detect small differences. On the basis of comparability the protocol of Horn and Scholz (2009) was not modified limiting the body-size estimation to one region of the lower extremity and to conditions without tactile stimuli. Using the silhouettetechnique, the students had to identify their actual perceived figure, their actual felt figure and their ideal figure from seven figure drawings of different shapes. The cognitiveaffective components of body experience were measured by questionnaires: the questionnaire for body image (FKB-20) presents the vital and dismissive body dynamic (Clement and Löwe, 1996) and the physical appearance state and trait anxiety score (PASTAS) measures body related fears (Reed et al., 1991). For stimulating the vestibular system we used a CVS with cold air, predominantly activating the horizontal semicircular canals (Palla and Lenggenhager, 2014). For practical reasons we chose the air-based CVS, even though we know about the converse discussion about comparability of water- and air-based methods (Zapala et al.,
2008). The study was approved by the local ethic committee (EK53032007).

The examination contained two appointments (each between 5 and $8 \mathrm{pm}$ ) for separated stimulation of left and right vestibular organ with an interval of at least $24 \mathrm{~h}$. After testing the requirements for CVS (ear mirroring using a portable otoscope, Unterberg-test, Romberg-test, nystagmus with Frenzel-glasses), the real thigh diameter (TW) was measured with an anthropometric calipers. After first estimation of TW (using both hands to show the felt TW with closed eyes), answering the questionnaires and a second estimation of TW before the CVS, the CVS was performed. Therefore we used the method according to Hallpike (1956) with $27^{\circ} \mathrm{C}$ tempered air (air-calorisator AIRMATIC II $^{\mathrm{TM}}$ by Hortmann) for $45 \mathrm{~s}$ with a subsequent 1 min counting of caloric induced nystagmus (Frenzelglasses) in a darkened room. The ear irrigation was followed by a third estimation of TW, another answering of the questionnaire and a fourth estimation of TW. After precisely adjusting the estimated TW with their hands (and covered eyes) before and after the CVS, the patients were invited to open their eyes and observe their estimated TW. The reaction of the participants regarding differences between estimated and real TW was not evaluated in this study. We used the Body-Perception-Index (Slade and Russell, 1973) as a quotient of estimated and real 


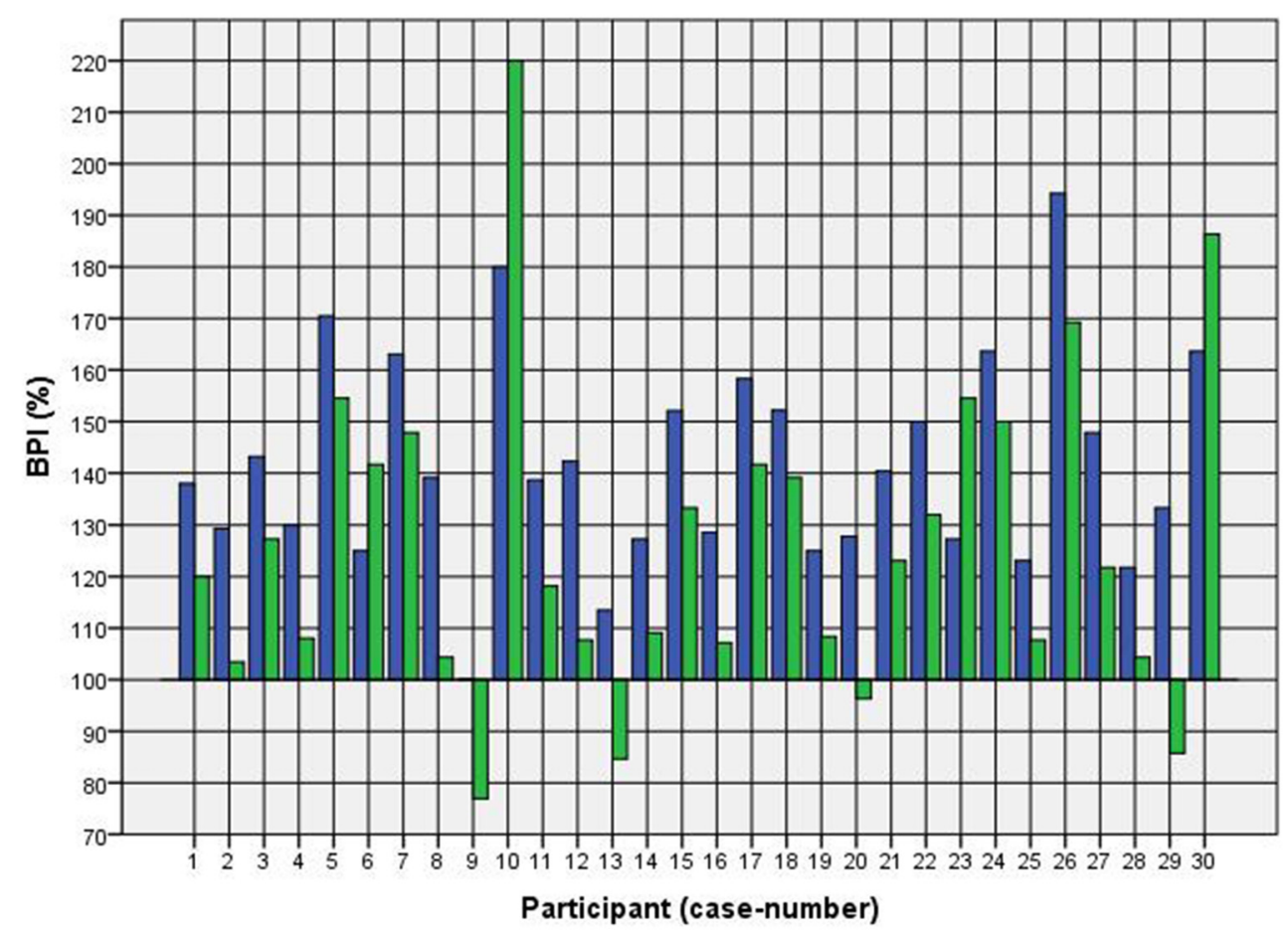

FIGURE 3 | BPI before and after right CVS. Key: blue-BPI before CVS; green-BPI after CVS. Annotation: BPI > 100\% means overestimation of TW; $\mathrm{BPI}<100 \%$ means underestimation of TW.

measurement of TW, which we calculated in the following way:

$$
B P I(\%)=\left(\frac{\text { estimated amount }}{\text { real amount }}\right) * 100
$$

A BPI over $100 \%$ means an overestimation and a BPI under $100 \%$ underestimation of the real body dimension.

For statistical analysis we used the Software SPSS (IBM) and the Wilcoxon signed-rank test for related samples. We compared the effect of CVS (induced eye movements) between left and right side, the results of body-size estimation before and after CVS respectively for left and right side and the change of BPI after CVS of right and left side.

\section{RESULTS}

\section{Characteristics of the Cohort}

The sample $(n=30)$ contained 22 females and 8 males participants $(\mathrm{P})$ between 18 and 31 years $(\phi 24.6 \pm 2.9$ years). Body size was located between 1.55 and $1.97 \mathrm{~m}(\phi 1.73 \pm 0.97 \mathrm{~m})$ and body weight between 51 and $100 \mathrm{~kg}(\phi 67 \pm 13 \mathrm{~kg})$. The BMI as an indicator of the size-related weight was between 18.9 and $26.4 \mathrm{~kg} / \mathrm{m}^{2}\left(\phi 22.3 \pm 2.2 \mathrm{~kg} / \mathrm{m}^{2}\right)$. Twenty-eight participants were right-handed and two left-handed. One participant reported recurrent vertigo attacks in stressful situations, two about hypothyroidism with intake of L-thyroxin, and two others about a nodular goiter. Eighteen of 22 females participants were on oral contraception. Two participants (P11/P16) reported recurrent distance-problems, which means, that they bump into things very often. A slimmer body was favored by 23 of 30 participants, six participants showed a desired body figure which corresponds to their actual perceived body figure, and one participant wanted a plumper figure (Additional aspects can be found in attachment 1).

\section{Estimation of Thigh Width}

Because of the small difference of $0.5 \mathrm{~cm}$ between the first and second basal TW estimation we selected the mean and compared it with the first estimation after CVS. The difference before-after was $0.8-5.0 \mathrm{~cm}(\phi 2.5 \pm 1.1 \mathrm{~cm})$ on the left and $1.5-5.0 \mathrm{~cm}(\phi 2.7 \pm 1.0 \mathrm{~cm})$ on the right side (Figure 1). This was statistically significant in the 5\% level (Wilcoxon signed-rank test for related samples). The difference before-after was greater or equal $1.5 \mathrm{~cm}$ in 27 participants. Most participants $(n=23)$ estimated their TW thinner than before, four participants estimated their TW wider, and three participants showed a difference between left and right side (Figure 1). The change in TW-estimation can also be seen in the Body Perception Index (BPI; Figures 2, 3): before CVS a general overestimation (BPI $>100 \%)$ was present with mild differences between the right and left side. Comparing the TW-estimation with the desired body-figure, we observed that all participants who favored a slimmer desired figure 


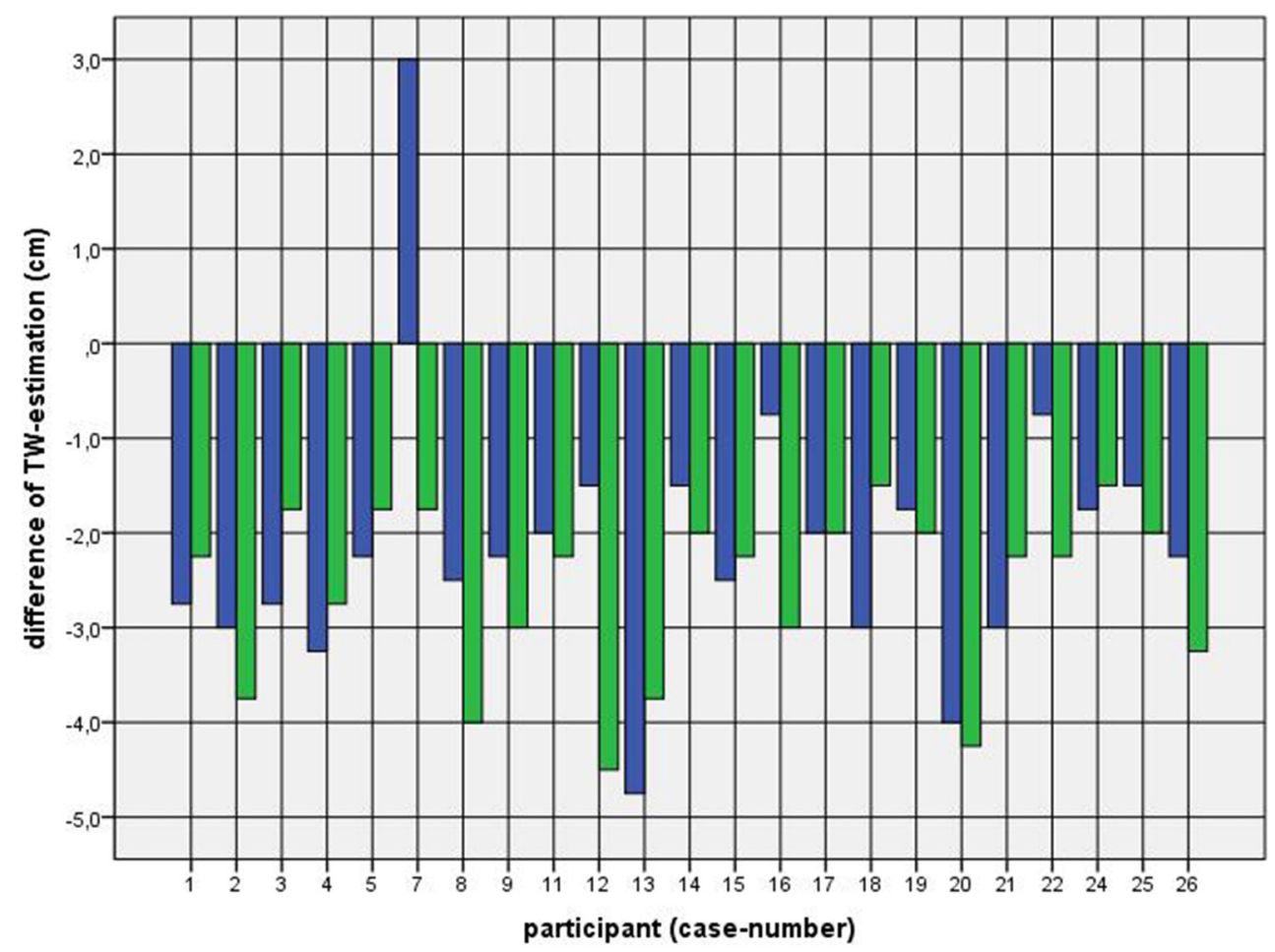

FIGURE 4 | Difference between mean of TW estimation before and first TW estimation after CVS among participants with a favored figure thinner than their actual perceived. Key: blue-first appointment, left-CVS; green-second appointment, right-CVS. Annotation: negative difference-first estimated TW after CVS was thinner than mean of TW-estimation before CVS; positive difference-first estimated TW after CVS was wider than mean of TW-estimation before CVS.

(except P7 after left CVS) estimated their TW after CVS of both sides thinner than before (Figure 4). This was not statistically significant. It is only an observed phenomenon. The participants, whose desired and actual figure matched, showed no clear direction in the change of TW-estimation CVS (Figure 5). The one participant who favored to be plumper estimated his TW wider after CVS. Even though a measurable change in TW-estimation after CVS was present in every participant, 26 of them were not aware of it. They were convinced of showing the same TW every time. Only four participants were uncertain with their TW-estimation after CVS, but did also not become aware of the present change.

Oral contraception had no specific effects on the tested outcome.

\section{Questionnaires}

The figure scale, the FKB-20 and the PASTAS showed no basal peculiarities and no statistically significant changes after CVS (A detailed evaluation can be found in attachment 2).

\section{DISCUSSION}

\section{Influence on Perceptive Component}

All participants showed a statistically significant change in their TW estimation after CVS. This might indicate that the vestibular system has a decisive role in the body image and the perceptive component of one's body experience. CVS seems to influence the components for perceiving the physical limits of one's body. This confirms the previous work (Ferrè et al., 2013a) concerning the influence of the vestibular system on the body-image. However, the method of CVS on body image related measurements was not tested by non-bodyrelated spatial distances. Therefore, a possibility of non-specific reaction on CVS remains to be ruled out and has to be addressed in further studies. In addition, the measurements included only the thigh which changes its width considerably between standing and sitting. It remains to be determined if estimations in other regions of the body show similar changes after CVS and if the thigh is therefore representative for this kind of perceptive body experience. Furthermore, no tactile stimuli for body size perception were included in this study. The estimation might therefore partially depend on cognitive aspects.

Participants, who wanted to be thinner, estimated their TW smaller after a CVS. Their TW overestimation was reduced after CVS. According to the theory of "sensory signal management" (Bottini et al., 2013) a vestibular stimulation can modulate sensory input between the environment and the body. This modulation can help to adjust information and better predict forthcoming perceptions with their resulting actions (Mast et al., 2014). Thus, it is conceivable that a vestibular stimulation might modulate the internal picture of the thigh in favor of 


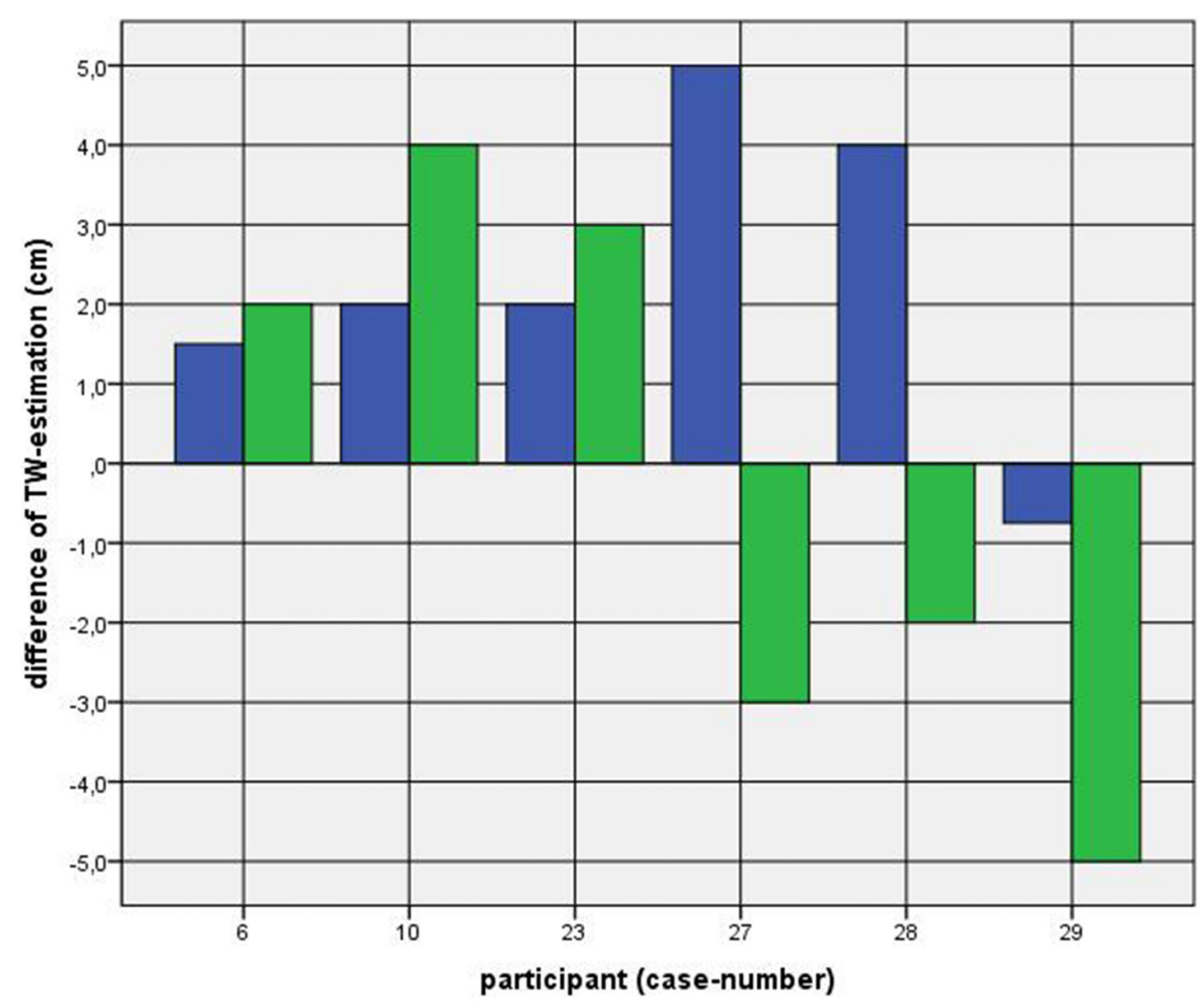

FIGURE 5 | Difference between mean of TW estimation before and first TW estimation after CVS among participants with a corresponding favored and actual figure. Key: blue-first appointment, left-CVS; green-second appointment, right-CVS. Annotation: negative difference-first estimated TW after CVS was thinner than mean of TW-estimation before CVS; positive difference-first estimated TW after CVS was wider than mean of TW-estimation before CVS.

a desired body image. The desired image might influence the somatosensory perceptual qualities, tonus and postural control which enable the adjustment of an "unaware, reality based, desired image".

Furthermore, the majority of participants did not become consciously aware of this change. We suppose that CVS is able to influence higher cortical centers but does not reach the level of consciousness. This is supported by the lack of changes within the questionnaires which require an awareness and conscious state. Although there is a known influence on the perceptive component of body experience, it's detection with the figure scale shows no statistically significant change after CVS. We conclude that a vestibular stimulation as performed in this study is not intense enough to reach the level of one's conscious state.

\section{Influence on Cognitive-Affective Component}

The specific cognitive-affective component, studied with questionnaires, revealed no statistically significant changes after CVS. However, some evidence from literature support the influence of the vestibular system on different phenomena requiring structural integrity of the cortex. Current studies show an influence of CVS on one's body-integrity, awareness and image (Ferrè et al., 2014) and on body movement (Guillaud et al., 2011). Why were we not able to demonstrate the influence of CVS on cognitive-affective components in our study? It might be possible that the intensity of caloric irrigation was not strong enough to reach the higher cortical centers. According to this we would recommend a stronger irrigation method (e.g., cold water) in future tests.

However, another aspect might also be taken into account: the vestibular system is a phylogenetic old system, located in the brain stem and inner ear. Although there are multiple synapsis in the cortex (Lopez et al., 2012), which can lead to a cortical processing and an influence of vestibular information, the vestibular system might not reach all areas in the phylogenetically younger cortex, necessary for one's conscious experience and reflection. We think that the questionnaires are probably not suitable for studying the influence of the vestibular system on body experience. Activities like the TW-estimation appear to better demonstrate the distorting influence of the caloric vestibular system on body experience.

A third aspect could also account for the steady answers of the questionnaires: cognitive body experiences might reflect a more steady state, and therefore less likely to be influenced by situational factors like CVS. 


\section{AUTHOR CONTRIBUTIONS}

All authors listed, have made substantial, direct and intellectual contribution to the work, and approved it for publication.

\section{ACKNOWLEDGMENTS}

The authors like to thank the team of the Audiometric Department at the University Clinic in Dresden for teaching the

\section{REFERENCES}

André, J. M., Martinet, N., Paysant, J., Beis, J. M., and Le Chapelain, L. (2001). Temporary phantom limbs evoked by vestibular caloric stimulation in amputees. Neuropsychiatry Neuropsychol. Behav. Neurol. 14, 190-196.

Bisiach, E., Rusconi, M. L., and Vallar, G. (1991). Remission of somatoparaphrenic delusion through vestibular stimulation. Neuropsychologia 29, 1029-1031. doi: 10.1016/0028-3932(91)90066-h

Bottini, G., Gandola, M., Sedda, A., and Ferrè, E. R. (2013). Caloric vestibular stimulation: interaction between somatosensory system and vestibular apparatus. Front. Integr. Neurosci. 7:66. doi: 10.3389/fnint.2013. 00066

Clement, U., and Löwe, B. (1996). Die Validierung des FKB-20 als Instrument zur Erfassung von Körperbildstörungen bei psychosomatischen Patienten. [Validation of the FKB-20 as scale for the detection of body image distortions in psychosomatic patients]. Psychother. Psychosom. Med. Psychol. 46, 254-259.

Curthoys, I. S., and Halmagyi, G. M. (1995). Vestibular compensation: a review of the oculomotor, neural and clinical consequences of unilateral vestibular loss. J. Vestib. Res. 5, 67-107. doi: 10.1016/0957-4271(94) 00026-X

Deroualle, D., and Lopez, C. (2014). Toward a vestibular contribution to social cognition. Front. Integr. Neurosci. 8:16. doi: 10.3389/fnint.2014. 00016

Ferrè, E. R., Day, B. L., Bottini, G., and Haggard, P. (2013a). How the vestibular system interacts with somatosensory perception: a sham-controlled study with galvanic vestibular stimulation. Neurosci. Lett. 550, 35-40. doi: 10.1016/j.neulet. 2013.06.046

Ferrè, E. R., Vagnoni, E., and Haggard, P. (2013b). Vestibular contributions to bodily awareness. Neuropsychologia 51, 1445-1452. doi: 10.1016/j. neuropsychologia.2013.04.006

Ferrè, E. R., Lopez, C., and Haggard, P. (2014). Anchoring the self to the body: vestibular contribution to the sense of self. Psychol. Sci. 25, 2106-2108. doi: 10. 1177/0956797614547917

Figliozzi, F., Guariglia, P., Silvetti, M., Siegler, I., and Doricchi, F. (2005). Effects of vestibular rotatory accelerations on covert attentional orienting in vision and touch. J. Cogn. Neurosci. 17, 1638-1651. doi: 10.1162/08989290577 4597272

Guillaud, E., Simoneau, M., and Blouin, J. (2011). Prediction of the body rotationinduced torques on the arm during reaching movements: evidence from a proprioceptively deafferented subject. Neuropsychologia 49, 2055-2059. doi: 10. 1016/j.neuropsychologia.2011.03.035

Hallpike, C. S. (1956). The caloric tests. J. Laryngol. Otol. 70, 15-28. doi: 10. $1017 /$ s0022215100052610

Horn, K., and Scholz, M. (2009). "Eine neue Methode zur Erfassung der Körperwahrnehmung bei Patienten mit Anorexia nervosa," in Körpererleben und Körperbild. Ein Handbuch zur Diagnostik, eds P. Joraschky, T. Loew and F. Röhricht (Stuttgart, New York, NY: Schattauer), 117-124.

Levine, J., Toder, D., Geller, V., Kraus, M., Gauchman, T., Puterman, M., et al. (2012). Beneficial effects of caloric vestibular stimulation on denial of illness and manic delusions in schizoaffective disorder: a case report. Brain Stimul. 5, 267-273. doi: 10.1016/j.brs.2011.03.004 technique of ear mirroring and caloric vestibular stimulation. We acknowledge support by the German Research Foundation and the Open Access Publication Funds of the TU Dresden for publication.

\section{SUPPLEMENTARY MATERIAL}

The Supplementary Material for this article can be found online at: http://journal.frontiersin.org/article/10.3389/ fnint.2016.00014/abstract

Lopez, C., Blanke, O., and Mast, F. W. (2012). The human vestibular cortex revealed by coordinate-based activation likelihood estimation meta-analysis. Neuroscience 212, 159-179. doi: 10.1016/j.neuroscience.2012.03.028

Mast, F. W., Preuss, N., Hartmann, M., and Grabherr, L. (2014). Spatial cognition, body representation and affective processes: the role of vestibular information beyond ocular reflexes and control of posture. Front. Integr. Neurosci. 8:44. doi: 10.3389/fnint.2014.00044

McKay, R., Tamagni, C., Palla, A., Krummenacher, P., Hegemann, S. C. A., Straumann, D., et al. (2013). Vestibular stimulation attenuates unrealistic optimism. Cortex 49, 2272-2275. doi: 10.1016/j.cortex.2013.04.005

Okada, Y., Kita, Y., Nakamura, J., Tanizawa, M., Morimoto, S., and Shomoto, K. (2012). Galvanic vestibular stimulation for camptocormia in Parkinson's disease: a case report. J. Nov. Physiother. S1:001. doi: 10.4172/2165-7025.S1-001

Palla, A., and Lenggenhager, B. (2014). Ways to investigate vestibular contributions to cognitive processes. Front. Integr. Neurosci. 8:40. doi: 10. 3389/fnint.2014.00040

Péruch, P., Lopez, C., Redon-Zouiteni, C., Escoffier, G., Zeitoun, A., Sanjuan, M., et al. (2011). Vestibular information is necessary for maintaining metric properties of representational space: evidence from mental imagery. Neuropsychologia 49, 3136-3144. doi: 10.1016/j.neuropsychologia.2011.07.026

Preuss, N., Hasler, G., and Mast, F. W. (2014a). Caloric vestibular stimulation modulates affective control and mood. Brain Stimul. 7, 133-140. doi: 10.1016/j. brs.2013.09.003

Preuss, N., Mast, F. W., and Hasler, G. (2014b). Purchase decision-making is modulated by vestibular stimulation. Front. Behav. Neurosci. 8:51. doi: 10 . 3389/fnbeh.2014.00051

Ramachandran, V. S., Blakeslee, S., Kober, H., Ramachandran-Blakeslee, and Sacks, O. (2004). Die Blinde Frau, die Sehen Kann: Rätselhafte Phänomene Unseres Bewusstseins. 2nd Edn. Reinbek bei Hamburg: Rowohlt-TaschenbuchVerl.

Reed, D. L., Thompson, J., Brannick, M. T., and Sacco, W. P. (1991). Development and validation of the physical appearance state and trait anxiety scale (PASTAS). J. Anxiety Disord. 5, 323-332. doi: 10.1016/0887-6185(91) 90032-o

Röhricht, F., Seidler, K.-P., Joraschky, P., Borkenhagen, A., Lausberg, H., Lemche, E., et al. (2005). Konsensuspapier zur terminologischen Abgrenzung von Teilaspekten des Körpererlebens in Forschung und Praxis. Psychother. Psychosom. Med. Psychol. 55, 183-190. doi: 10.1055/s-2004 834551

Schönherr, A., and May, C. A. (2015). Influence of caloric vestibular stimulation on body experience of anorectic patients. Int. J. Case Stud. 4, 13-17.

Skworzoff, K. (1931). Doppelgänger-Halluzinationen bei Kranken mit Funktionsstörungen des Labyrinths. Z. Gesamte Neurol. Psychiatr. 133, 762-766. doi: 10.1007/bf02909953

Slade, P. D., and Russell, G. F. (1973). Awareness of body dimensions in anorexia nervosa: cross-sectional and longitudinal studies. Psychol. Med. 3, 188-199. doi: 10.1017/S0033291700048510

Smith, P. F., and Darlington, C. L. (2013). Personality changes in patients with vestibular dysfunction. Front. Hum. Neurosci. 7:678. doi: 10.3389/fnhum.2013. 00678

Smith, P. F., Geddes, L. H., Baek, J.-H., Darlington, C. L., and Zheng, Y. (2010). Modulation of memory by vestibular lesions and galvanic vestibular stimulation. Front. Neurol. 1:141. doi: 10.3389/fneur.2010. 00141 
Thompson, J. K. (1999). Exacting Beauty: Theory, Assessment and Treatment of Body Image Disturbance. 1st Edn. Washington, DC: American Psychological Association.

Thompson, M. A., and Gray, J. J. (1995). Development and validation of a new body-image assessment scale. J. Pers. Assess. 64, 258-269. doi: 10. 1207/s15327752jpa6402_6

Zapala, D. A., Olsholt, K. F., and Lundy, L. B. (2008). A comparison of water and air caloric responses and their ability to distinguish between patients with normal and impaired ears. Ear Hear. 29, 585-600. doi: 10.1097/aud. ob013e3181734ed0
Conflict of Interest Statement: The authors declare that the research was conducted in the absence of any commercial or financial relationships that could be construed as a potential conflict of interest.

Copyright (c) 2016 Schönherr and May. This is an open-access article distributed under the terms of the Creative Commons Attribution License (CC BY). The use, distribution and reproduction in other forums is permitted, provided the original author(s) or licensor are credited and that the original publication in this journal is cited, in accordance with accepted academic practice. No use, distribution or reproduction is permitted which does not comply with these terms. 